\title{
TOP CITED PAPERS IN INTERNATIONAL PSYCHOGERIATRICS: 6b. BEHAVIORAL DISORDERS AND CAREGIVERS' REACTION IN TAIWANESE PATIENTS WITH ALZHEIMER'S DISEASE
}

\section{Reflection}

The behavioral and psychological symptoms of dementia (BPSD) are common and serious problems that affect the quality of life of the patients who experience such symptoms as well as their caregivers (Matsui et al., 2006). BPSD present a major challenge in the medical management of cognitively impaired patients. Our paper entitled "Behavioral disorders and caregivers' reaction in Taiwanese patients with Alzheimer's disease" (hereafter referred to as the "paper") (Fuh et al., 2001) has been cited widely, reflecting the importance of these clinical issues and the growing international interest in studies of BPSD.

A valid and reliable evaluating instrument is essential to detect and study BPSD. The aims of the paper were to evaluate the applicability of the Chinese (Taiwanese) version of the Neuropsychiatric Inventory (NPI) (Cummings et al., 1994), and to explore the neuropsychiatric manifestations of Taiwanese patients with Alzheimer's disease (AD) and the associated caregiver distress (Fuh et al., 2001). The NPI was developed to assess psychopathology in dementia patients and is one of the most commonly used instruments to evaluate BPSD. It evaluates 10 neuropsychiatric disturbances often observed in dementia: delusions, hallucinations, agitation, dysphoria, anxiety, apathy, irritability, euphoria, disinhibition and aberrant motor behavior. The night-time behavior disturbances and appetite and eating abnormalities were added to the NPI later (NPI-12) (Cummings, 1997). A nursing home version also was developed for use by professional caregivers within institutions (Wood et al., 2000). The severity and frequency of each neuropsychiatric symptom are rated on the basis of scripted questions administered to the patient's caregiver. The NPI also assesses caregiver distress engendered by each of the neuropsychiatric disorders. The NPI provides a clear and simple description of each symptom and assists researchers and clinicians to better define each symptom of BPSD. The high cross-cultural reliability of the NPI is based on its highly structured format and scripted questions.

We have reviewed the 32 articles that cited our paper and discovered that 18 of them $(56.2 \%)$ found the paper of interest because it provided evidence of the existence of neuropsychiatric sub-syndromes in dementia. Six articles (18.9\%) cited the paper because of cross-cultural comparisons of BPSD, a growing area of interest in dementia and BPSD research.

BPSD refers to a heterogeneous range of psychological reactions, psychiatric symptoms, and behaviors occurring in people with dementia. Factor analysis techniques have been used to explore behavioral dimensions that may comprise BPSD. Table 1 summarizes studies using factor analytic techniques to identify the subsyndromes contained within the NPI (Frisoni et al., 1999; Fuh et al., 2001; Aalten et al., 2003; Lange et al., 2004; Mirakhur et al., 2004; Borroni et al., 2006; Hollingworth et al., 2006; Matsui et al., 2006; Aalten et al., 2007; Zuidema et al., 2007). Three to five sub-syndromes were found in these studies and different terms were used to label them. Despite some differences among these studies, the associations of the following symptoms were very consistent: (1) depression and anxiety, (2) delusions and symptoms of hallucination, (3) agitation and irritability, (4) disinhibition and euphoria. The symptoms were in the same subsyndrome in most of the reviewed studies and across various cultural settings, suggesting that these four common sub-syndromes may reflect four distinctive pathophysiological disorders (Robert et al., 2005). More studies are needed to determine if these four sub-syndromes also share treatment-related characteristics.

Apathy and aberrant motor activities are two symptoms that had variable associations with other individual symptoms in different patient populations. Apathy was associated with depression in some studies (Aalten et al., 2003; 2007; Hollingworth et al., 2006), with aberrant motor activities in others (Frisoni et al., 1999; Lange et al., 2004; Mirakhur et al., 2004; Matsui et al., 2006; Zuidema et al., 2007), or with other symptoms in some studies (Fuh et al., 2001; Borroni et al., 2006; Zuidema et al., 2007). The relationship between depression and apathy is controversial. It is recognized that apathy overlaps with depression, which is not surprising considering that common symptoms of both syndromes include diminished motivation and interest as well as lack of insight. The major difference is that apathy may occur in the absence of depressed mood. One study showed that 


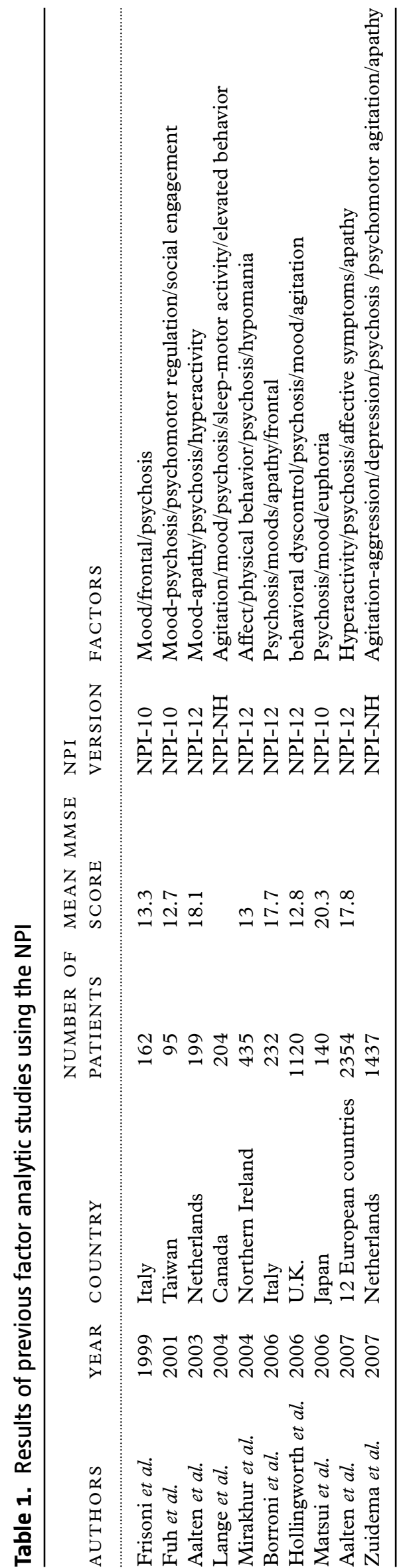

the associations of apathy with depression changed as the disease progressed (Hollingworth et al., 2006), possibly explaining some conflicting study results. Studies using positron emission tomography (PET) and single emission computed tomography (SPECT) to establish regional cerebral metabolism or perfusion showed that regions of dysfunction associated with these two syndromes were different. Patients with apathy showed involvement of the anterior cingulate and related frontal-subcortical circuit structures (Craig et al., 1996; Benoit et al., 1999), patients with depression evidenced more abnormalities of frontal, temporal and parietal areas (Starkstein et al., 1995; Hirono et al., 1998).

Aberrant motor activities had no consistent associations with any individual symptoms. Aberrant motor activities comprise symptoms like pacing, constant opening/closing wardrobes, repeatedly dressing or undressing and picking/fiddling or other repetitive behavior (Cummings et al., 1994). This syndrome is least well understood of all those identified by the NPI and warrants further study.

BPSD no doubt stem from a complex interaction among biological, environmental and cultural factors (Fuh et al., 2002). Similar behavioral sub-syndromes identified across different cultures suggests that the observed behaviors are more related to a common underlying biological dysfunction whereas differing patterns of behavior may indicate that cultural or environmental influences may be more relevant. Our previous transcultural study (Fuh et al., 2002) of three countries - Taiwan, Italy and the U.S.A. showed a significant relationship between agitation and hallucinations in the Taiwanese group and a significant relationship between agitation and apathy in the Italian group. In the American group, agitation and irritability were associated. We found different behavioral profiles accompanying agitation in the three cultural groups. This study highlighted the importance of cultural factors in some symptoms of BPSD.

Many transcultural questions pertaining to dementia remain unanswered, and there is a relative paucity of research on dementia in nonWestern societies. The conduct of cross-cultural studies using standardized sampling, diagnostic and assessment methods could contribute to our understanding of the interplay between genetic and environmental risk factors. Including our Chinese version, the NPI has been translated into a variety of languages with proven validity and reliability (Hirono et al., 1997; Binetti et al., 1998; Choi et al., 2000; Fuh et al., 2001; Leung et al., 2001; Baiyewu et al., 2003; Lange et al., 2004; Politis et al., 2004; Camozzato et al., 2008, Selbæk et al., 2008), facilitating further transcultural study of BPSD. 
This study followed a period during which Dr. Fuh trained with Dr. Cummings at UCLA. Dr. Fuh became familiar with research strategies and approaches involving the NPI and related assessments. Successful implementation of these skills in Taiwan resulted in the study documented in the paper. Such cross-national training is essential to enhance research worldwide.

Many new agents are evolving for the treatment of AD (Salloway et al., 2008). To build sufficient sample size to test these agents, global trials will be required. Cross-cultural studies of instruments such

\section{Commentary}

As Fuh and Cummings point out above, it is no coincidence that their paper (Fuh et al., 2001) was equal sixth in the number of citations received by all papers published in International Psychogeriatrics to the end of 2006 with 31 citations. This is because BPSD encompass key elements of the dementia syndrome and are prime drivers of major shifts in care and treatment. To underline the initial point, the first patient with Alzheimer's disease ever to be described, Augusta D, had prominent agitated behavior and intermittent delusional ideas (Maurer et al., 2006). To address the second point, very few people with dementia get admitted to residential care because they cannot remember the date, and even fewer are prescribed antipsychotic drugs because they cannot spell "world" backwards. Behaviors whose expression is captured by the NPI, such as sleep disturbance, excess motor activity and resistiveness to care, are common reasons for dedicated family members to acknowledge with reluctance that they can no longer care for the person they love at home and to seek that person's admission to residential care. Delusions, hallucinations, misidentifications and aggressive behavior are frequent indications leading to the prescription of antipsychotic drugs, which have the potential both to help and to harm patients (Suh, 2009) and the NPI is designed to note the presence, intensity and caregiver distress produced by these symptoms. The importance and topicality of this area of research is illustrated by a quick flick through the last three years of this journal's regular issues from December 2006 to October 2009 (18 issues). Of 48 review articles published over this period, ten $(20.8 \%)$ (Filan and LlewellynJones, 2006; Lyketsos, 2007; Konovalov et al., 2008; von Gunten et al., 2008; Beaulieu-Bonneau and Hudon, 2009; Haw et al., 2009; Kverno et al., 2009; O'Connor et al., 2009a; 2009b; Rodda et al., 2009) dealt with some aspect of the BPSD spectrum in as those conducted with NPI are critically important to designing and interpreting the data from these trials.

\author{
JONG-Ling FuH ${ }^{1}$ AND JEFFrey L. CUMmings ${ }^{2}$ \\ ${ }^{1}$ The Neurological Institute, Taipei Veterans General \\ Hospital, School of Medicine, National Yang-Ming \\ University, Taipei, Taiwan \\ ${ }^{2}$ Departments of Neurology and Psychiatry and \\ Biobehavioral Sciences, David Geffen School of \\ Medicine at UCLA, Los Angeles, CA, U.S.A. \\ Email: jcummings@mednet.ucla.edu
}

people with cognitive impairment, while 26 of 233 original research articles (11.2\%) (Holmes et al., 2006; Lövheim et al., 2006; 2008; 2009a; 2009b; Svansdottir and Snaedal, 2006; Bird et al., 2007; Davison et al., 2007; Kessing et al., 2007; Lanctôt et al., 2007; Liu et al., 2007; Rabinowitz et al., 2007; Cankurtaran et al., 2008; Haw et al., 2008; Nakaaki et al., 2008; Rozzini et al., 2008; Treiber et al., 2008; Borroni et al., 2009; Burns et al., 2009; Eggermont et al., 2009; Kleijer et al., 2009; Nijk et al., 2009; van der Geer et al., 2009; Weamer et al., 2009; Woods et al., 2009; Wu et al., 2009) also focused upon BPSD in dementia and related conditions in some shape or form.

Because dementia is a global challenge of rapidly growing proportions, and one that is growing fastest in the developing world (Ferri et al., 2005), we need translations of instruments which will be useful in populations whose languages are not those of the instruments' original designers, most of whom have developed their tools to be used in the English language. Again, International Psychogeriatrics illustrates this point. Since December 2006, 20 original research articles (Hendrie et al., 2006; Awata et al., 2007; Chachamovich et al., 2007; Falk et al., 2007; Malakouti et al., 2007; Nuevo et al., 2007; Tsai et al., 2007; Camozzato et al., 2008; Chaaya et al., 2008; Chu and Chung, 2008; Leung et al., 2008; Selbæk et al., 2008; Skjerve et al., 2008; van der Roest et al., 2008; Dodge et al., 2009; Fernandes et al., 2009; Gibbons et al., 2009; Perrocco et al., 2009; Tiwari et al., 2009; Wong and Fong, 2009), representing $8.6 \%$ of all such articles published in the journal that address the translation or validation of rating scales or assessment instruments in languages other than English, have been published within these pages. The International Psychogeriatric Association (IPA) exists partly in order to promote the spread of knowledge and to enable dissemination of best practice in order to benefit everyone in the world in relation to mental 
health and illness in late life, no matter where they live. Fuh et al. illustrated in their article the importance of this activity, and it is no coincidence that it has been highly cited. Its continued frequent citation is one illustration of the fact that IPA's journal continues to fulfill at least some of the objectives of IPA's founders and their successors

\section{DAVID AMES}

Editor-in-Chief International Psychogeriatrics, Melbourne, Australia

Email: ipaj-ed@unimelb.edu.au

\section{References}

Aalten, P. et al. (2003). Behavioral problems in dementia: a factor analysis of the Neuropsychiatric Inventory. Dementia and Geriatric Cognitive Disorders, 15, 99-105.

Aalten, P. et al. (2007). Neuropsychiatric syndromes in dementia: results from the European Alzheimer Disease Consortium: Part I. Dementia and Geriatric Cognitive Disorders, 24, 457-463.

Awata, S. et al. (2007). Validity and utility of the Japanese version of the WHO-Five Well-Being Index in the context of detecting suicidal ideation in elderly community residents. International Psychogeriatrics, 19, 77-88.

Baiyewu, O. et al. (2003). Behavioral and caregiver reaction of dementia as measured by the neuropsychiatric inventory in Nigerian community residents. International Psychogeriatrics, 15, 399-409.

Beaulieu-Bonneau, S. and Hudon, C. (2009). Sleep disturbances in older adults with mild cognitive impairment. International Psychogeriatrics, 21, 654-666.

Benoit, M. et al. (1999). Behavioral and psychological symptoms in Alzheimer's disease. Dementia and Geriatric Cognitive Disorders, 10, 511-517.

Binetti, G. et al. (1998). Behavioral disorders in Alzheimer disease: a transcultural perspective. Archives of Neurology, 55, 539-544.

Bird, M., Llewellyn-Jones, R. H., Korten, A. and Smithers, H. (2007). A controlled trial of a predominantly psychosocial approach to BPSD: treating causality. International Psychogeriatrics, 19, 874-891.

Borroni, B. et al. (2006). Genetic correlates of behavioral and phenotypes in Alzheimer disease: role of COMT, 5-HTTLPR and APOE polymorphisms. Neurobiology of Aging, 27, 1595-1603.

Borroni, B., Alberici, A., Agosti, C., Cosseddu, M. and Padovani, A. (2009). Pattern of behavioral disturbances in corticobasal degeneration syndrome and progressive supranuclear palsy. International Psychogeriatrics, 21, 463-468.

Burns, A., Allen, H., Tomenson, B., Duignan, D. and Byrne, J. (2009). Bright light therapy for agitation in dementia: a randomized controlled trial. International Psychogeriatrics, 21, 711-721.

Camozzato, A. L. et al. (2008). Reliability of the Brazilian Portuguese version of the Neuropsychiatric Inventory (NPI) for patients with Alzheimer's disease and their caregivers. International Psychogeriatrics, 20, 383-393.
Cankurturan, E. S., Kutluer, I., Senturk, M., Erzin, G. B., Gursay, D. and Tombak, E. (2008). Psychiatric consultations for nursing home residents: a perspective from Turkey and implications for comparable countries. International Psychogeriatrics, 20, 752-763.

Chachamovich, E., Trentini, C. and Fleck, M. P. (2007). Assessment of the psychometric performance of the WHOQOL-BREF instrument in a sample of Brazilian older adults. International Psychogeriatrics, 19, 635-646.

Chaaya, M. et al. (2008). Validation of the Arabic version of the short Geriatric Depression Scale (GDS-15). International Psychogeriatrics, 20, 571-581.

Choi, S. H., Na, D. L., Kwon, H. M., Yoon, S. J., Jeong, J. H. and Ha, C. K. (2000). The Korean version of the neuropsychiatric inventory: a scoring tool for neuropsychiatric disturbance in dementia patients. fournal of Korean Medical Science, 15, 609-615.

Chu, T. K. C. and Chung, J. C. C. (2008). Psychometric evaluation of the Chinese version of the Activities of Daily living Questionnaire (ADLQ-CV). International Psychogeriatrics, 20, 1251-1261.

Craig, A. H. et al. (1996). Cerebral blood flow correlates of apathy in Alzheimer disease. Archives of Neurology, 53, 1116-1120.

Cummings, J. L. (1997). The Neuropsychiatric Inventory: assessing psychopathology in dementia patients. Neurology, 48, S10-S16.

Cummings, J. L. et al. (1994). The Neuropsychiatric Inventory: comprehensive assessment of psychopathology in dementia. Neurology, 44, 2308-2314.

Davison, T., Hudgson, C., McCabe, M. P., George, K. and Buchanan, G. (2007). An individualized psychosocial approach for "treatment resistant" behavioral symptoms of dementia among aged care residents. International Psychogeriatrics, 19, 859-873.

Dodge, H. H., Meguro, K., Ishii, H., Yamaguchi, S., Saxton, J. A. and Ganguli, M. (2009). Cross-cultural comparison of the Mini-mental State Examination between Japanese and U.S. cohorts. International Psychogeriatrics, 21, 113-122.

Eggermont, L. H. P., de Vries, K. and Scherder, J. A. (2009). Psychotropic medication use and cognition in institutionalized older adults with mild to moderate dementia. International Psychogeriatrics, 21, 286-294.

Falk, H., Persson, L-O. and Wijk, H. (2007). A psychometric evaluation of a Swedish version of the Quality of Life in Late-Stage Dementia (QUALID) scale. International Psychogeriatrics, 19, 1040-1050.

Fernandes, L. et al. (2009). Validation study of the Camberwell Assessment of Need for the Elderly (CANE) in Portugal. International Psychogeriatrics, 21, 94-102.

Ferri, C. et al. (2005). Global prevalence of dementia: a Delphi consensus study. Lancet, 366, 2112-2117.

Filan, S. L. and Llewellyn-Jones, R. (2006). Animalassisted therapy for dementia: which interventions work and how large are their effects? International Psychogeriatrics, 18, 597-611.

Frisoni, G. B. et al. (1999). Behavioral syndromes in Alzheimer's disease: description and correlates. Dementia and Geriatric Cognitive Disorders, 10, 130-138.

Fuh, J. L., Liu, C. K., Mega, M. S., Wang, S. J. and Cummings, J. L. (2001). Behavioral disorders and 
caregivers' reaction in Taiwanese patients with Alzheimer's disease. International Psychogeriatrics, 13, 121-128.

Fuh, J. L., Mega, M. S., Binetti, G., Wang, S. J., Magni, E. and Cummings, J. L. (2002). A transcultural study of agitation in dementia: environmental influences and associated behaviour. Fournal of Geriatric Psychiatry and Neurology, 15, 171-174.

Gibbons, L. E. et al. (2009). Japanese-English language equivalence of the Cognitive Abilities Screening Instrument among Japanese-Americans. International Psychogeriatrics, 21, 129-137.

Haw, C., Stubbs, J. and Yorston, G. (2008). Antipsychotics for BPSD: an audit of prescribing practice in a specialist psychiatric inpatient unit. International Psychogeriatrics, 20, 790-799.

Haw, C., Harwood, D. and Hawton, K. (2009). Dementia and suicidal behavior: a review of the literature. International Psychogeriatrics, 21, 440-453.

Hendrie, H. C. et al. (2006). The development of a semi-structured home interview (CHIF) to directly assess function in cognitively impaired people in two cultures. International Psychogeriatrics, 18, 653-666.

Hirono, N. et al. (1997). Japanese version of the Neuropsychiatric Inventory - a scoring system for neuropsychiatric disturbance in dementia patients [in Japanese]. No To Shinkei, 49, 266-271.

Hirono, N. et al. (1998). Frontal lobe hypometabolism and depression in Alzheimer's disease. Neurology, 50, 380-383.

Hollingworth, P. et al. (2006). Four Components Describe Behavioral Symptoms in 1,120 individuals with late-onset Alzheimer's disease. Fournal of the American Geriatrics Society, 54, 1348-1354.

Holmes, C., Knights, A., Dean, C., Hodkinson, S. and Hopkins, V. (2006). Keep music live: music and the alleviation of apathy in dementia subjects. International Psychogeriatrics, 18, 623-630.

Kessing, L. V., Harhoff, M. and Andersen, P. K. (2007). Treatment with antidepressants in patients with dementia a nationwide register-based study. International Psychogeriatrics, 19, 902-913.

Kleijer, B. C. et al. (2009). The course of behavioral problems in elderly nursing home patients when treated with antipsychotics. International Psychogeriatrics, 21, 931-940.

Konovalov, S., Muralee, S. and Tampi, R. R. (2008). Anticonvulsants for the treatment of behavioral and psychological symptoms of dementia: a literature review. International Psychogeriatrics, 20, 293-308.

Kverno, K. S., Black, B. S., Nolan, MT. and Rabins, P. (2009). Research on treating neuropsychiatric symptoms of advance dementia with non-pharmacological strategies, 1998-2008: a systematic literature review. International Psychogeriatrics, 21, 825-843.

Lanctôt, K. L., Herrmann, N., Rothenburg, L. and Eryavec, G. (2007). Behavioral correlates of GABAergic disruption in Alzheimer's disease. International Psychogeriatrics, 19, 151-158.

Lange, R. T., Hopp, G. S. and Kang, N. (2004). Psychometric properties and factor structure of the Neuropsychiatric Inventory Nursing Home version in an elderly neuropsychiatric population. International fournal of Geriatric Psychiatry, 19, 440-448.
Leung, G. T. K., de Jong, J. and Lam, L. C. W. (2008). Validation study of the Chinese translation of the 6-item de Jong Gierveld Loneliness scale in elderly Chinese. International Psychogeriatrics, 1262-1272.

Leung, V. P., Lam, L. C., Chiu, H. F., Cummings, J. L. and Chen, Q. L. (2001). Validation study of the Chinese version of the neuropsychiatric inventory (CNPI). International fournal of Geriatric Psychiatry, 16, 789-793.

Liu, C-Y., Wang, P-N., Lin, K-N. and Liu, H-C. (2007). Behavioral and psychological symptoms in Taiwanese patients with Alzheimer's disease. International Psychogeriatrics, 19, 607-613.

Lövheim, H., Sandman, P-O., Kallin, K., Karlsson, S. and Gustafson, Y. (2006). Relationship between antipsychotic drug use and behavioral and psychological symptoms of dementia in old people with cognitive impairment living in geriatric care. International Psychogeriatrics, 18, 713-726.

Lövheim, H., Sandman, P-O., Karlsson, S. and Gustafson, Y. (2008). Behavioral and psychological symptoms of dementia in relation to level of cognitive impairment. International Psychogeriatrics, 20, 777-789.

Lövheim, H., Sandman, P-O., Karlsson, S. and Gustafson, Y. (2009a). Sex differences in the prevalence of behavioral and psychological symptoms of dementia. International Psychogeriatrics, 21, 469-475.

Lövheim, H., Sandman, P-O., Karlsson, S. and Gustafson, Y. (2009b). Changes between 1982 and 2000 in the prevalence of behavioral symptoms and psychotropic drug treatment among old people with cognitive impairment in geriatric care. International Psychogeriatrics, 21, 941-948.

Lyketsos, C. (2007). Neuropsychiatric symptoms (behavioral and psychological symptoms of dementia) and the development of dementia treatments. International Psychogeriatrics, 19, 409-420.

Malakouti, S. K., Fatollahi, P., Mirabzadeh, A. and Zandi, T. (2007). Reliability, validity and factor structure of the GHQ-28 used among elderly Iranians. International Psychogeriatrics, 19, 623-634.

Matsui, T. et al. (2006). Determinants of the quality of life in Alzheimer's disease patients as assessed by the Japanese version of the Quality of Life-Alzheimer's disease scale. Dementia and Geriatric Cognitive Disorders, 21, 182-191.

Maurer, K., Cummings, J., McKeith, I., Ames, D. and Burns, A. (2006). Has treatment for Alzheimer's disease changed over the last 100 years? Lancet, 358, 1619-1621.

Mirakhur, A., Craig, D., Hart, D. J., Mcllroy, S. P. and Passmore, A. P. (2004). Behavioural and psychological syndromes in Alzheimer's disease. International fournal of Geriatric Psychiatry, 19, 1035-1039.

Nakaaki, S. et al. (2008). Association between apathy/depression and executive function in patients with Alzheimer's disease. International Psychogeriatrics, 20, 964-975.

Nijk, R. M., Zuidema, S. U. and Koopmans, R. T. C. M. (2009). Prevalence and correlates of psychotropic drug use in Dutch nursing-home patients with dementia. International Psychogeriatrics, 21, 485-493.

Nuevo, R., Mackintosh, M-A., Gatz, M., Montorio, I. and Loebach Wetherell, J. (2007). A test of the measurement invariance of a brief version of the Penn State 
Worry questionnaire between American and Spanish older adults. International Psychogeriatrics, 19, 89-101.

O'Connor, D. W., Ames, D., Gardner, B. and King, $M$. (2009a). Psychosocial treatments of behavior symptoms in dementia: a systematic review of reports meeting quality standards. International Psychogeriatrics, 21, 225-240.

O'Connor, D. W., Ames, D., Gardner, B. and King, $M$. (2009b). Psychosocial treatments of psychological symptoms in dementia: a systematic review of reports meeting quality standards. International Psychogeriatrics, 21, 241-251.

Perrocco, T. R. et al. (2009). Performance of Brazilian long and short IQCODE on the screening of elderly people with low education. International Psychogeriatrics, 21, 531-538.

Politis, A. M., Mayer, L. S., Passa, M., Maillis, A. and Lyketsos, C. G. (2004). Validity and reliability of the newly translated Hellenic Neuropsychiatric Inventory (H-NPI) applied to Greek outpatients with Alzheimer's disease: a study of disturbing behaviors among referrals to a memory clinic. International fournal of Geriatric Psychiatry, 19, 203-208.

Rabinowitz, J., Katz, I., De Deyn, P., Greenspan, A. and Brodaty, H. (2007). Treating behavioral and psychological symptoms in patients with psychosis of Alzheimer's disease using risperidone. International Psychogeriatrics, 19, 227-240.

Robert, P. H. et al. (2005). Grouping for behavioral and psychological symptoms in dementia: clinical and biological aspects. Consensus paper of the European Alzheimer's Disease Consortium. European Psychiatry, 20, 490-496.

Rodda, J., Morgan, S. and Walker, Z. (2009). Are cholinesterase inhibitors effective in the management of the behavioral and psychological symptoms of dementia in Alzheimer's disease? A systematic review of randomized, placebo-controlled trials of donepezil, rivastigmine and galantamine. International Psychogeriatrics, 21, 813-824.

Rozzini, L. et al. (2008). Mild parkinsonian signs and psycho-behavioral symptoms in subjects with mild cognitive impairment. International Psychogeriatrics, 20, 86-95.

Salloway, S., Mintzer, J., Weiner, M. F. and Cummings, J. L. (2008). Disease-modifying therapies in Alzheimer's disease. Alzheimer's Dementia, 4, 65-79.

Selbæk, G., Kirkevold, Ø., Sommer, O. H. and Engedal, K. (2008). The reliability and validity of the Norwegian version of the Neuropsychiatric Inventory, Nursing Home Version (NPI-NH). International Psychogeriatrics, 20, 375-382.

Skjerve, A. et al. (2008). Validation of the Seven Minute Screen and Syndrome Kurztest among elderly Norwegian outpatients. International Psychogeriatrics, 20, 807-814.

Starkstein, S. E., Vazquez, S., Migliorelli, R., Teson, A., Sabe, L. and Leiguarda, R. (1995). A single-photon emission computed tomographic study of anosognosia in Alzheimer's disease. Archives of Neurology, 52, 415-420.

Suh, G-H. (2009). The use of atypical antipsychotics in dementia: rethinking Simpson's paradox. International Psychogeriatrics, 21, 616-621.

Svansdottir, H. B. and Snaedal, J. (2006). Music therapy in moderate and severe dementia of Alzheimer's type: a case-control study. International Psychogeriatrics, 18, 613-621.

Tiwari, S. C., Tripathi, R. K. and Kumar, A. (2009). Applicability of the Mini-mental State Examination (MMSE) and the Hindi Mental State Examination (HMSE) to the urban elderly in India: a pilot study. International Psychogeriatrics, 21, 123-128.

Treiber, K. A. et al. (2008). Vascular factors and risk for neuropsychiatric symptoms in Alzheimer's disease: the Cache County Study.International Psychogeriatrics, 20, 538-553.

Tsai, R-C., Lin, K-N., Wang, H-J. and Liu, H-C. (2007). Evaluating the use of the total score and the domain scores in the Cognitive Abilities Screening Instrument, Chinese Version (CASI C-2.0): results of a confirmatory factor analysis. International Psychogeriatrics, 19, 1051-1063.

van der Geer, E. R., Vink, A. C., Schols, G. M. G. A. and Slaets, J. P. J. (2009). Music in the nursing home: hitting the right note! The provision of music to dementia patients with verbal and vocal agitation in Dutch nursing homes. International Psychogeriatrics, 21, 86-93.

van der Roest, H. G., Meiland, F. J. M., van Hout, H. P. J., Jonker, C. and Dröes, R-M. (2008). Validity and reliability of the Dutch version of the Camberwell Assessment of Need for the Elderly in community-dwelling people with dementia. International Psychogeriatrics, 20, 1273-1290.

von Gunten, A., Alnawaqil, A-M., Abderhalden, C., Needham, M. and Schupbach, B. (2008). Vocally disruptive behavior in the elderly: a systematic review. International Psychogeriatrics, 20, 653-672.

Weamer, E. A. et al. (2009). The relationship of excess cognitive impairment in MCI and early Alzheimer's disease to the subsequent emergence of psychosis. International Psychogeriatrics, 21, 78-87.

Wong, S. S. and Fong, K. N. K. (2009). Reliability and validity of the telephone version of the Cantonese Mini-mental State Examination (T-CMMSE) when used with elderly patients with and without dementia in Hong Kong. International Psychogeriatrics, 21, 345-353.

Wood, S. et al. (2000). The use of the neuropsychiatric inventory in nursing home residents: characterization and measurement. American fournal of Geriatric Psychiatry, 8, 75-83.

Woods, D. L., Bushnell, B., Kim, H., Geschwind, D. and Cummings, J. (2009). Apolipoprotein $\varepsilon 4$ status is associated with behavioral symptoms in nursing home residents with dementia. International Psychogeriatrics, 21, 722-728.

Wu, H. Z. Y., Low, L-F., Xiao, S. and Brodaty, H. (2009). A pilot study of differences in behavioral and psychological symptoms of dementia in nursing home residents in Sydney and Shanghai. International Psychogeriatrics, 21, 476-484.

Zuidema, S. U., de Jonghe, J. F. M., Verhey, F. R. J. and Koopmans, R. T. C. M. (2007). Neuropsychiatric symptoms in nursing home patients: factor structure invariance of the Dutch nursing home version of the Neuropsychiatric Inventory in different stages of dementia. Dementia and Geriatric Cognitive Disorders, 24, 169-176. 